\section{A NATIONAL MEDICAL SERVICE.}

To the Eiditor of THE LANCET.

SIR,-In view of the widespread publicity given by the lay press to Sir John Collie's suggestion of a State Medical Service, which is being held to be necessary by very many who are conversant with the absolute inefficiency and breakdown of the panel system, you may be able to publish the following suggestions for a Royal Health Medical Service, which I desired to make in the medical press some time ago :-

\section{Suggestions for a Royal Health Medical Service.}

1. That His Majesty the King should be graciously pleased, on the advice of his Ministers, to institute a Royal Health Medical Service on a similar basis to that of the Royal Navy and Royal Army Medical Services ; this would not only be a great honour to the prcfession, but would also be of the greatest material service to the members who are now struggling in acute competition.

2. That the service should be directly controlled and administered by a Secretary of State responsible to Parliament; with this the objection, so strongly held, to the control of Friendly Societies, or of bodies dominated by them, would be obviated.

3. That the medical officers appointed should be granted relative rank with the officers of the other Royal services, with titular distinction as a reward for exceptional or long service and the use of the letters R.H.M.S. after their names. Such a service would have no difficulty in attracting highly qualified and experienced physicians and surgeons as specialists and consultants, and would raise the standing of medical men all over the country.

4. A thoroughly efficient and full medical service could be given to workmen and their dependents and to all others who are not in a position to pay for medical advice.

5. The service should include within its ranks all medical men engaged in the various civilian medical services, phrsicians and surgeons of hospitals, medical officers of health, sanatorium medical officers, medical referees under the Workmen's Compensation and National Insurance Acts, and, when the promised reform has arrived, the present infirmary and Poor-law medical officers.

6. It is admitted that the reform of the Poor-law cannot be long delayed, as both political parties are anxious to take the stigma of pauperism from the poor who may be in receipt of medical benefit, and whatever may be the status of a patient the same skill and attention is required for the restoration of health or the relief of suffering. There seems to be no reason, therefore, why the poor should not be attended by a branch of the Royal Health Medical Service or by medical officers of the service generally employed.

7. If appointments as senior and junior medical officers were offered at salaries approximating to those usual in the Ropal Navy and Army Medical Services there would be no lack of candidates, and later on selection by competitive examination would be necessary. In sparsely populated districts part-time medical officers might be appointed with retaining salary or visitir $g$ and attendance fees.

8. That properly furnished and fitted clinics should be provided in populous districts, so that the objections which have been raised to the supply of drugs and dressings by retail chemists on contract would be met, and the best drugs, antiseptic dressings, and appliances could be obtained at first hand at the lowest possible price, owing to the large quantity which would be required and which could be had at wholesale prices. Qualified dispensers, male and female, could be obtained in any number, at reasonable salaries.

9. The Insurance Commissioners would be relieved from the heavy duties necessitated by the supervision of the appointment of the present panel service and would be able more efficiently to control the Approved Societies and the papment of claims.

10. As probably the great majority of the present panel doctors would accept service under the State with adequate salaries and retiring pensions, the "free choice of a doctor" could be largely retained, subject to a strict limitation of the list of any individual medical officer, so that his patients could be efficiently and promptly attended without overwork.
I have abstained from attacking the present panel system, although the system is by many condemned as the worst form of contract service yet known, with its competition for patients, and whe inefficioncy of the medical attendance when large panels are hold. Insurance offices are being very hardly hit, as it is in many cases impossible to procure for a workman proper attendance, the hospitals referring men to their panel doctors, and the panel doctors being without time properly to attend to dressings, massage, \&c.

I am, Sir, yours faithfully,

South Hampstead, N.W., Jan. 15th, 1914. Albert Benthald,

\section{To the Editor of I'HE LANCET.}

SIR,-After a careful consideration of the points raised by Sir John Collie in his recent lecture, "The Medical Man and the National Insurance Act," and his deductions therefrom, I cannot help thinking that if the case for a National Medical Service can be defended by no better arguments than are there put forward it is weak in the extreme. Doubtless he puts his fingers on certain defects in the Iusurance Act and its present administration, but none of them are irremediable, and it is generally admitted that with suitable amendment its provisions might be made accept. able to nearly the whole profession. What may be unhesitatingly stated is that much as it is disliked now by certain sections of the profession none but an insignificant minority would exchange it for a State Medical Service. Some of Sir John Collie's statements are certainly open to criticism. Dealing with "Defects in Central Administration" he says :-

It was clear to those who went into the question at the time, and it is now admitted by all, that the agitation of the British Medical Association was largely based on a misconception. Elementary as the mistake may be, it is undoubtedly the fact that many doctors had the belief that the payment was to be per patient and not per person.

I can only characterise this as a plain misstatement of fact. I was on the Council of the Association and a representative of my division throughout the whole of the agitation that preceded the passing of the Act, and as such met representatives from all parts of the country. Among those who had any. thing to do with framing the policy of the Association I do not think there was any one who entertained such a delusion. Yet Sir John Collie says, "The agitation of the British Medical Association was largely based on this elementary misconception!"

Dealing with "defects inherent in the panel system," he complains of the "non-selection of the doctors." "For the army and navy a searching examination must be passed, for the Poor-law service, the school doctors, and the Post Office service, appointments are advertised, and the best man who presents himself is selected." Here, again, Sir John Collie's statements are at variance with the fact. Ordinary Post Office appointments are rarely, if ever, advertised. Again, if the various appointments specified are advertised, does the best man who presents himself get the appointment? If this is Sir John Collie's experience it is not mine. I think a statement that it was the exception for the best man to get the appointment, and when he did it was for some other reason than his professional excellence, would be much nearer the truth. Again, under a National Medical Service, if only the best men are going to 
be selected what becomes of the mediocrity of the profession? Are they to compete outside with the State doctors? The choice of an intelligent patient of his own doctor is at least as good as that made usually by a public board on his behalf. In either case a mistake can be made and often is, but it can be corrected much more readily in the former than the latter case.

In the picture Sir John Collie draws of a National Medical Service, it is easy to detect a glamour similar to that thrown on their pictures by con. fessed socialists when endeavouring to point out the advantages of the socialistic state. Sir John Collie says the changes he proposes will be to many practitioners " highly distasteful." I must reckon myself among that number, but not simply because the changes are "distasteful," but because in my opinion they are bad both for the public and the profession. If I believed in Socialism, that is in the State undertaking everything for every. body, and individual enterprise and independence being relegated more and more to the back. ground, it might be otherwise. As it is, I regard honest competition with one's fellows, with all its drawbacks, as a more honourable position for a medical practitioner than to become a unit in any National Medical Service; and I am of opinion that medical science will be best promoted, and the welfare of the nation best maintained in the future, as in the past, by an independent profession of medicine.

I am, Sir, yours faithfully,

Hackney-road, N.E., Jan. 18th, 1914. MAJOR GREENWOOD.

\section{THE TREATMENT OF GRANULAR KIDNEY. To the Editor of THE LANCET.}

SIR,-I regret that owing to my not having been able to get the corrected proof of my letter on this subject ${ }^{1}$ returned to the offices of THE LANCET in time for the press an error has crept in. Where the letter (in the second line from the top of the right hand column of page 210 ) states " in 24 hours the pulse was 94," it ought to read "in 48 hours," \&c.-I am, Sir, yours faithfully,

Cliftonville, Margate, Jan, 19th, 1914.

$$
\text { A. Graham-Stewart. }
$$

1 The LANCET, Jan. 17th, 1914, p. 209.

Royal ANThropological Institute. - The president and council of the institute will entertain Professor Baldwin Spencer, C.M.G., F.R.S., of Melbourne University, at a complimentary dinner at the Café Monico, London, W., on Jan. 27th, at 6.30 P.M.

Societr for RElief of Widows and ORPhANS OF MEDICAL MEN. - A quarterly court of directors of this society was held on Jan. 14th, Dr. Rigden, senior vice-president present, being in the chair. Fifteen members of the court were present. Since the last court two of the vice-presidents of the society had died-Dr. Clement Godson and Mr. H. W. Kiallmark. One of the widows in receipt of grants had also died; she came on the funds in 1875, and received in grants the sum of $£ 2300$. Her hnsband had paid in subscriptions $£ 3716 s$. The sum of $£ 1260$ was voted to pay the usual half-yearly grants to the widows and orphans, and £392 10s. were voted for special grants to be paid out of the Brickwell Fund. The invested funds of the society now amount to $£ 139,500$. Membership of the society is open to any registered medical practitioner who at the time of his election is resident within a 20 -mile radius of Charing Cross. The annual subscription is 2 guineas. Special terms for life membership. Further particulars and application forms for membership may be obtained by applying to the secretary at the office of the society, 11, Chandos-street, Carendish-square, London, W.

\section{THE NATIONAL INSURANCE ACT.}

The State Medical Service Question.

IN delivering the first of a series of lectures arranged by the Faculty of Insurance, dealing with various aspects of National Insurance, Sir John Collie took as his subject "The Medical Profession and National Insurance," and after criticising severely what he indicated as the defects of medical service under the panel system, advocated strongly recourse to a National Medical Service as a remedy Sir John Collie regarded as a mistake the admission to the panels of all proposing themselves, irrespec. tive of character and qualifications. He spoke of men who had never established themselves in prac. tices of any value as having now large numbers of in. sured patients, and contrasted with this system that which provided practitioners for the army and navy, and for appointments such as those offered by the Poor-law Service or the Post Office. He also called attention to the competition between medical men which was encouraged by the system, and referred to it as producing touting and other unprofessional practices. He was of the opinion that excessively large panel lists were producing scamped and inferior work, giving as an instance the experience of a panel practitioner who had told him that he had to see 50 or 60 patients every evening. He con. sidered that a State Medical Service was the best remedy for this state of affairs and the best means for bringing the advantages of medical science within the reach of the insured. He considered that such a service would be more economical than the present system, and that without interfering with private practice would offer opportunities to those in its lower ranks to rise to eminence, it members doing their best to keep themselves abreast of modern science. We referred in a leading article last week to one great argument againsta State Medical Service-at any rate, in the present position of medical practice. When the combina. tion of a choice of doctor by the insured with a regimented service is considered, the path advo cated by Sir John Collie is seen to be diffcult, while some of his criticisms on the working of the Act are being directly contradicted.

\section{MEDICAI REFEREES AS UNDERSTOOD BY SOME} APPROVED SOCIETIES.

A letter to the Daily News recently recommended the formation of "complaints committees" as a solution of "the difficulty as regards satisfactor: attendance by panel doctors," and went on to call attention, surely somewhat inconsequently, to a practice for which panel doctors are in no war responsible. According to the writer "a large number of persons who have claimed sick pay on the certificate of their panel doctor are sent to another medical gentleman appointed by the Approved Society. The panel dootor says the person is unfit for work. The referee examines the patient and reports to the societs that the person is not unfit." The writer after illustrating the hardship which is thus inflicted upon the sick person by reference to an instance which occurred within his knowledge, continues: "This is happening all over the country. Whose word are we to take-that of the panel doctor who administers to the patient, or the referee appointed by the society?" The point raised is a very im. portant one. It was referred to in THE LANCET 0 Dec. 13th last, p. 1734, in connexion with a case which 